\title{
Application of the functional capacity scale in the early assessment of functional efficiency in patients after aneurysm embolization: Preliminary reports
}

\author{
Robert Ślusarz ${ }^{1, A-D, F}$, Monika Biercewicz'2, C, D, F, Barbara Smarszzz ${ }^{3, B, C, E, F}$, Maria Szewczyk ${ }^{4, C, E, F}$, \\ Joanna Rosińczuk ${ }^{5, C, E, F}$, Maciej Śniegocki ${ }^{3, C, E, F}$ \\ ${ }^{1}$ Neurological and Neurosurgical Nursing Department, Faculty of Health Sciences, Collegium Medicum, Nicolaus Copernicus University, Toruń, Poland \\ ${ }^{2}$ Clinic of Geriatrics, Faculty of Health Sciences, Collegium Medicum, Nicolaus Copernicus University, Toruń, Poland \\ ${ }^{3}$ Neurotraumatology Department, Faculty of Health Sciences, Collegium Medicum, Nicolaus Copernicus University, Toruń, Poland \\ ${ }^{4}$ Department of Surgical Nursing, Chair of Perioperative Nursing, Faculty of Health Sciences, Collegium Medicum, Nicolaus Copernicus University, Torun, Poland \\ ${ }^{5}$ Department of Nervous System Diseases, Faculty of Health Science, Wroclaw Medical University, Poland
}

A - research concept and design; $\mathrm{B}$ - collection and/or assembly of data; $\mathrm{C}$ - data analysis and interpretation;

$D$ - writing the article; $E$ - critical revision of the article; $F$ - final approval of article

\section{Address for correspondence}

Robert Ślusarz

E-mail:zpielnin@cm.umk.pl

Funding sources

None declared

Conflict of interest

None declared

\section{Acknowledgements}

The authors are grateful to Janice L. Hinkle, PhD, RN, CNRN, the Catholic University of America, School of Nursing, for assistance and valuable suggestions.

Received on 0ctober 11, 2015 Revised on January 26, 2016 Accepted on February 17, 2016

DOI

$10.17219 /$ acem/61832

\section{Copyright}

Copyright by Author(s)

This is an article distributed under the terms of the Creative Commons Attribution Non-Commercial License (http://creativecommons.org/licenses/by-nc-nd/4.0/)

\begin{abstract}
Background. While data on the long-term (e.g., 1 year and subsequent years) outcomes of intracranial aneurysms treatment is relatively well-documented mainly in the clinical aspect (comparability of treatment, mortality, and complications), little is known about the early results, in terms of the functional outcome.

Objectives. The aim of the study was to analyze the use of Functional Capacity Scale (FCS) in the evaluation of patients in the early period after endovascular treatment of intracranial aneurysms.

Material and methods. The study was conducted in the Neurosurgery Clinic, University Hospital Collegium Medicum in Bydgoszzz, on a group of 118 consecutively admitted patients with the diagnosis of intracranial aneurysm, qualified for treatment using the endovascular method (embolization). The assessment was performed twice. In the clinical assessment the Glasgow Coma Scale (GCS) was used to evaluate the level of consciousness and the Hunt and Hess Scale (H\&H) to assess the patient's condition. To assess the final outcome and early functional capacity Glasgow Outcome Scale (GOS), Barthel Index (BI), Modified Rankin Scale (mRS) and the new Functional Capacity Scale were used.
\end{abstract}

Results. The assessment performed with the FCS was comparable to the assessment conducted with standardized tools such as BI, mRS or GOS. The clinical condition assessed with the GCS ( $p<0.001)$ and $H \& H(p<0.001)$ differentiates the functional condition assessed using the FCS. Statistically significant correlations were found between FCS and BI $(r=-0.78), G 0 S(r=-0.69)$ and $m R S(r=0.68)$.

Conclusions. The study indicates that the FCS correlates with other scales used in the assessment of patients with intracranial aneurysm, which means that the proposed tool can be applied successfully in practice. However, further randomized multicenter studies are necessary in order to clarify the final conclusion.

Key words: functional assessment, outcome, aneurysm, subarachnoid hemorrhage 
The death rate caused by SAH from ruptured intracranial aneurysm decreased in the recent decades by ca. $17 \%$ and the overall survival rate amounts to ca. $65 \%{ }^{1,2}$ This is due to, among others factors, aneurysms being secured earlier, better understanding of the pathophysiology of angiospasm, as well as more aggressive and earlier praphylaxis and treatment of systemic complications. ${ }^{2}$ Undoubtedly, considerable progress in the intensive treatment, diagnostics and accessibility to intracranial treatment contributed to the marked improvement in the results of treatment in patients after SAH caused by ruptured intracranial aneurysm, mainly from the long-term aspect. ${ }^{3-5}$

While the data on long-term results (i.e. after a year and longer) of intracranial aneurysm treatment are fairly well documented $^{6-9}$, mainly from the clinical aspect (comparison of treatment methods, mortality, complications occurrence), there is a lack of data on early results from the functional aspect. The immediate period following the procedure (time until the patient's discharge) is particularly dangerous for the patient due to the possibility of various complications appearing that may affect his or her functional capacity. A well-performed early functional assessment may provide prognosis regarding long-term results.

Research carried out for many years showed that one of the most important factors conditioning the result of treatment, as well as the functional result of patients with aneurysm (with/without SAH), is the patient's clinical condition (including consciousness level) prior to treatment. The analysis of the clinical condition and consciousness of patients with an aneurysm is usually conducted with scales such as the Glasgow Coma Scale (GCS), Hunt and Hess Scale $(\mathrm{H} \& \mathrm{H})$ and the World Federation of Neurological Surgeons Scale (WFNS). ${ }^{10-12}$ Their functional condition, on the other hand, is usually assessed with scales such as the Barthel Index (BI), Modified Rankin Scale (mRS), and Glasgow Outcome Scale (GOS). ${ }^{13-15}$

The main aim of the study was to analyze the performance of the Functional Capacity Scale (FCS) in the assessment of patients in the early period following the endovascular treatment of intercranial aneurysm. Possible correlations between the scales used for the assessment of the functional condition of a patient were investigated. Moreover, an attempt was made to determine whether clinical condition assessed with the Glasgow Coma Scale and the Hunt and Hess Scale provide similar results to the Functional Capacity Scale, Barthel Index, Modified Rankin Scale and the Glasgow Outcome Scale.

\section{Material and methods}

\section{Setting and sample}

The study was conducted at the Neurosurgery Clinic of the University Hospital Collegium Medicum (CM) in By-
Table 1. Demographic data regarding the study participants N (\%)

\begin{tabular}{|c|c|}
\hline \multicolumn{2}{|c|}{ Gender } \\
\hline Female & $73(61.9)$ \\
\hline Male & 45 (38.1) \\
\hline \multicolumn{2}{|c|}{ Age } \\
\hline$\leq 49$ & $51(43.2)$ \\
\hline $50-64$ & 55 (46.6) \\
\hline$\geq 65$ & $12(10.2)$ \\
\hline \multicolumn{2}{|c|}{ Location of aneurysms* } \\
\hline $\mathrm{ACOA}$ & $42(35.6)$ \\
\hline ICA & $33(28.0)$ \\
\hline MCA & $22(18.6)$ \\
\hline VBA & $21(17.8)$ \\
\hline \multicolumn{2}{|c|}{ Clinical display } \\
\hline Unruptured aneurysm & $42(35.6)$ \\
\hline Ruptured aneurysm - SAH & $76(64.4)$ \\
\hline \multicolumn{2}{|c|}{ Time for embolization } \\
\hline$\leq 24$ & $85(72.0)$ \\
\hline $25-71$ & $15(12.7)$ \\
\hline$\geq 72$ & $18(15.3)$ \\
\hline \multicolumn{2}{|c|}{ GCS } \\
\hline I (15-13) & $100(84.8)$ \\
\hline II (12-9) & $11(9.3)$ \\
\hline III (8-3) & $7(5.9)$ \\
\hline \multicolumn{2}{|c|}{$\mathrm{H} \& \mathrm{H}$} \\
\hline 0 & $42(35.6)$ \\
\hline$|-| \mid$ & $58(49.2)$ \\
\hline III & $11(9.3)$ \\
\hline IV-V & $7(5.9)$ \\
\hline
\end{tabular}

*ACoA - anterior communicating artery (and location on the anterior cerebral artery); ICA - internal carotid artery; MCA - medial carotid artery, VBA - vertebral-basilar artery. 
dgoszcz, Nicolaus Copernicus University (NCU) in Torun. The study involved patients admitted with a diagnosed intracranial aneurysm and qualified for endovascular treatment (embolization). The patients chosen for the study had to meet the following criteria: 1) be diagnosed for intracranial aneurysm and 2) undergo a successful embolization procedure (for the first time) 3) with no fatal complications. The criteria that eliminated a patient from the study included: 1) being diagnosed with more than 1 intracranial aneurysm (consecutive aneurysm) or other vasal anomaly (i.a. arteriovenous angioma), 2) having undergone consecutive and/or unsuccessful embolization or surgery procedure (clipping, wrapping, trapping), 3) fatal complications.

Among the 118 patients there were 73 women and 45 men. The age of the patients ranged from 18 (the youngest) to 82 (the oldest). The average age was $51.4 \pm 11.4$, with patients of age 50-64 being the most numerous group. All the patients were hospitalized for intracranial aneurysm and all of them underwent an embolization procedure. Seventy-six patients were diagnosed with ruptured aneurysm (with subarachnoid haemorrhage - SAH), and 42 were suffering from non-ruptured aneurysm (i.e. cold). The aneurysm was usually located in the complex of the anterior communicating artery (42 persons) and the internal carotid artery (33 persons). The average time preceding the embolization procedure was $43 \mathrm{~h}$. The largest number of patients (85) underwent embolization up to $24 \mathrm{~h}$ after having been admitted to the ward (Table 1).

\section{Instruments}

The study involved a two-time assessment. The first assessment (measure 1 - prior to the procedure) was conducted on the first day of patient's hospitalization. The clinical assessment involved the use of the Glasgow Coma Scale (GCS) to measure the patient's level of consciousness, and the Hunt and Hess Scale (H\&H) to assess the patient's condition. ${ }^{10,11}$ The second assessment (measure 2 - after the procedure) was carried out on the day of the patient's discharge from the ward. The end results and the patient's functional capacity were assessed with the Glasgow Outcome Scale (GOS), Barthel Index (BI), Modified Rankin Scale (mRS), and the proposed Functional Capacity Scale (FCS) (Table 2)..$^{13-17}$

\section{Ethical considerations}

The study obtained the consent of the Bioethics Commission of the Nicolaus Copernicus University in Torun at Ludwik Rydygier Collegium Medicum in Bydgoszcz (KB no. 297/2008, no. 291/2013, and no. 564/2014).

\section{Data analysis}

The statistical analysis was conducted with the Microsoft Excel programme (licence CM NCU LOGON S.A.,
Table 2. Condition on the day of discharge (after the procedure) N (\%)

\begin{tabular}{|c|c|}
\hline \multicolumn{2}{|c|}{ FCS } \\
\hline I & 98 (83.1) \\
\hline$\|$ & $11(9.3)$ \\
\hline III & $4(3.4)$ \\
\hline IV & $5(4.2)$ \\
\hline \multicolumn{2}{|r|}{$\mathrm{Bl}$} \\
\hline V & $52(44.1)$ \\
\hline IV & $41(34.7)$ \\
\hline III & $13(11.0)$ \\
\hline$\|$ & $6(5.1)$ \\
\hline I & $6(5.1)$ \\
\hline \multicolumn{2}{|c|}{$\mathrm{mRS}$} \\
\hline 0 & $52(44.1)$ \\
\hline 1 & $37(31.4)$ \\
\hline 2 & $9(7.6)$ \\
\hline 3 & $8(6.8)$ \\
\hline 4 & $8(6.8)$ \\
\hline 5 & $4(3.4)$ \\
\hline \multicolumn{2}{|c|}{ GOS } \\
\hline 5 & 65 (55.1) \\
\hline 4 & $34(28.8)$ \\
\hline 3 & 16 (13.6) \\
\hline 2 & $3(2.6)$ \\
\hline 1 & $0(0)$ \\
\hline
\end{tabular}

Bydgoszcz, PL) and STATISTICA v. 10.0. (licence CM NCU, StatSoft, Kraków, PL). The analysis of conformity of quantitative variables to normal distribution was carried out with the Shapiro-Wilk test. Following the accepted parameters in biomedical sciences, unless stated differently, the results were acknowledged as statistically significant at a value of 0.05. The analysis used the Kruskal-Wallis non-parametric Anova test and a post-hoc test to determine any statistically significant differences between the 
assessment of the patient's consciousness level (GCS) and his or her clinical condition $(\mathrm{H} \& \mathrm{H})$, and the patient's functional capacity after treatment. Moreover, the study involved the use of Spearman's rank correlation coefficient $\left(r_{S}\right)$ to indicate the relationship between its value and the individual tools used to assess the patient's functional capacity (FCS, BI, mRS and GOS).

\section{Results}

On the day of the patient's discharge from the ward (Table 2), in accordance with the FCS classification adopted, the largest number of patients was found in group I (98 persons - 83\%). This means that the early results regarding the functional capacity in the analysed group are successful. The fact is further confirmed by the results obtained with the standardized functional scales. The BI identified 93 persons as "able" (BI group $\mathrm{V}$ and IV). Similarly, the mRS estimated the number of people in good condition to 89 (mRS group 0 and 1). The Glasgow Outcome Scale, on the other hand, qualified 99 persons to group 5 and 4, indicating satisfactory result of treatment.

Furthermore, we analysed the influence of the consciousness level according to the GCS scale and clinical condition in the $\mathrm{H} \& \mathrm{H}$ scale (prior to the procedure) on the patient's functional capacity after receiving endovascual treatment of aneurysm as assessed with the functional scales (FCS, BI, mRS, GOS). The value of test statistics in the analysis of the influence of consciousness level (GCS) on the patient's functional capacity (Table 3 ) is statistically significant at $\mathrm{p}<0.001$. Statistically significant differences among all the analysed groups in accordance with the FCS, BI, mRS and GOS scales were found, which means that patients with a higher level of consciousness obtained better functional result. Similarly, the patient's clinical condition prior to the procedure assessed with the $H \& H$ (Table 4), significantly $(\mathrm{p}<0.001)$ differentiated functional capacity after the procedure; thus, the patients in better clinical condition obtained better functional result.

Individual tools for the functional assessment were compared (Table 5). Each case provided a statistically significant value of the Spearman's rank correlation coefficient in the range from 0.68 to -0.88 . The highest coefficient in the correlation analysis with the FCS was obtained for the BI $\left(r_{S}=-0.78\right)$, and the lowest for the mRS $\left(r_{S}=0.68\right)$. A comparison of the remaining scales' correlations showed the highest coefficient $\left(r_{S}=-0.88\right)$ for the GOS and mRS. Thus, there is a relationship between the FCS results and the results obtained with each individual scale (BI, mRS, GOS), which means that they influence one another in a statistically significant ways; hence, they are mutually dependant.
Table 3. Dependency of functional capacity (FCS, BI, mRS, GOS) from the level of consciousness (GCS)

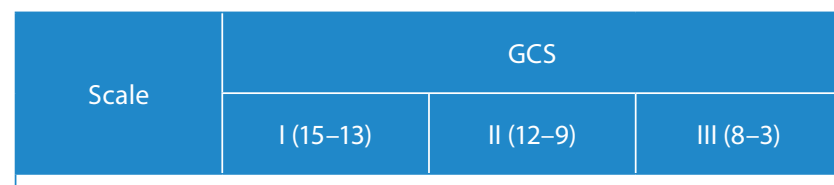

FCS - test ANOVA rank Kruskal-Wallis $\mathrm{H}(\mathrm{df}=2, \mathrm{n}=118)=45.17 ; \mathrm{p}<0.001$

\begin{tabular}{|l|c|c|c|}
\hline $\mathrm{X} \pm \mathrm{SD}$ & $46.1 \pm 2.9$ & $32.6 \pm 8.1$ & $21.1 \pm 6.4$ \\
\hline Me & 47 & 33 & 19 \\
\hline Range & $35-48$ & $16-40$ & $15-31$ \\
\hline
\end{tabular}

$\mathrm{BI}$ - test ANOVA rank Kruskal-Wallis $\mathrm{H}(\mathrm{df}=2, \mathrm{n}=118)=49.92 ; \mathrm{p}<0.001$

\begin{tabular}{|l|c|c|c|}
\hline $\mathrm{X} \pm \mathrm{SD}$ & $92.8 \pm 10.6$ & $47.7 \pm 11.7$ & $22 \pm 3.9$ \\
\hline $\mathrm{Me}$ & 100 & 50 & 20 \\
\hline Range & $60-100$ & $20-70$ & $20-30$ \\
\hline
\end{tabular}

mRS - test ANOVA rank Kruskal-Wallis $\mathrm{H}(\mathrm{df}=2, \mathrm{n}=118)=47.37 ; \mathrm{p}<0.001$

\begin{tabular}{|l|c|c|c|}
\hline $\mathbf{X} \pm \mathrm{SD}$ & $0.65 \pm 0.84$ & $3.18 \pm 0.98$ & $4.43 \pm 0.53$ \\
\hline Me & 0 & 3 & 4 \\
\hline Range & $0-4$ & $2-5$ & $4-5$ \\
\hline
\end{tabular}

GOS - test ANOVA rank Kruskal-Wallis $\mathrm{H}(\mathrm{df}=2, \mathrm{n}=118)=44.41 ; \mathrm{p}<0.001$

\begin{tabular}{|l|c|c|c|}
\hline$x \pm S D$ & $4.60 \pm 0.59$ & $3.36 \pm 0.50$ & $2.57 \pm 0.53$ \\
\hline Me & 5 & 3 & 3 \\
\hline Range & $3-5$ & $3-4$ & $2-3$ \\
\hline
\end{tabular}

x - average; SD - standard deviation; Me - median; range - range of points for the scale.

\section{Discussion}

The study involved an early assessment of functional capacity in patients with intracranial aneurysm treated by means of endovascular embolization. The authors believe this is the first such study regarding early-term results from the point of view of functional assessment, which is particularly significant for making prognoses on long-term results (e.g. 3-6-12 months after the procedure). Apart from the applied standardized functional scales (BI, mRS, GOS), the results were supplemented with the proposed FCS scale. ${ }^{17}$

The research tools used in the study consisted of the most popular and reliable scales applied in the assessment of patients with aneurysm and SAH. It was confirmed by Al-Khindi et al. ${ }^{18}$, who presented a literature review on Cognitive and Functional Outcome After Aneurysmal 
Table 4. Dependency of functional capacity (FCS, BI, mRS, GOS) from clinical condition (H\&H)

\begin{tabular}{|c|c|c|c|c|}
\hline \multirow{2}{*}{$\mathrm{Sca}$} & \multicolumn{4}{|c|}{$\mathrm{H} \& \mathrm{H}$} \\
\hline & 0 & $|-| \mid$ & III & $I V-V$ \\
\hline \multicolumn{5}{|c|}{ FCS - test ANOVA rank Kruskal-Wallis $\mathrm{H}(\mathrm{df}=3, \mathrm{n}=118)=60.76 ; \mathrm{p}<0.001$} \\
\hline$x \pm S D$ & $47.1 \pm 2.2$ & $45.3 \pm 3.1$ & $32.6 \pm 8.1$ & $21.1 \pm 6.4$ \\
\hline Me & 48 & 46 & 33 & 19 \\
\hline Range & $35-48$ & $35-48$ & $16-40$ & $15-31$ \\
\hline \multicolumn{5}{|c|}{$\mathrm{BI}$ - test ANOVA rank Kruskal-Wallis $\mathrm{H}(\mathrm{df}=3, \mathrm{n}=118)=64.39 ; \mathrm{p}<0.001$} \\
\hline$x \pm S D$ & $96.4 \pm 9.4$ & $90.2 \pm 10.6$ & $47.7 \pm 11.7$ & $22.1 \pm 3.9$ \\
\hline $\mathrm{Me}$ & 100 & 95 & 50 & 20 \\
\hline Range & $60-100$ & $70-100$ & $20-70$ & $20-30$ \\
\hline \multicolumn{5}{|c|}{$m R S$ - test ANOVA rank Kruskal-Wallis $H(d f=3, n=118)=60.66 ; p<0.001$} \\
\hline$x \pm S D$ & $0.26 \pm 0.54$ & $0.93 \pm 0.92$ & $3.18 \pm 0.98$ & $4.43 \pm 0.53$ \\
\hline $\mathrm{Me}$ & 0 & 1 & 3 & 4 \\
\hline Range & $0-2$ & $0-4$ & $2-5$ & $4-5$ \\
\hline \multicolumn{5}{|c|}{ GOS - test ANOVA rank Kruskal-Wallis $\mathrm{H}(\mathrm{df}=3, \mathrm{n}=118)=50.02 ; \mathrm{p}<0.001$} \\
\hline$x \pm S D$ & $4.79 \pm 0.47$ & $4.47 \pm 0.63$ & $3.36 \pm 0.50$ & $2.57 \pm 0.53$ \\
\hline Me & 5 & 5 & 3 & 3 \\
\hline Range & $3-5$ & $3-5$ & $3-4$ & $2-3$ \\
\hline
\end{tabular}

x - average; SD - standard deviation; Me - median; range - range of points for the scale.

In most cases the functional assessment is carried out alongside multicentre trials, such as the International Subarachnoid Aneurysm Trial (ISAT) ${ }^{6-8}$ and the Barrow Ruptured Aneurysm Trial (BRAT) ${ }^{9}$, which feature very long monitoring periods but are predominantly oriented towards comparing the results of intravascular and surgery treatment with respect to mortality and compilations occurrence.

One of the main factors that affects the results of treatment in patients suffering from intracranial aneurysm is their clinical conditions prior to the treatment ${ }^{19-21}$. The majority of the conducted analyses indicate that the clinical condition and the level of consciousness of patients on the day of admission constitute an independent prognostic factor for long-term results of treatment.

The presented material shows a significant relationship between the clinical condition assessed with the use of the $\mathrm{H} \& \mathrm{H}$ and the patient's consciousness level assessed with the GCS on the day of admission, and the functional result of discharge. Both the $\mathrm{H} \& \mathrm{H}$ and GCS scales showed that the more severe condition upon patients' admission translated into worse functional capacity upon their discharge, which was confirmed with three different measuring instruments (mRS, BI and FCS).

The research by Haug et al. ${ }^{22}$ showed that 1 in 5 patients admitted to hospital after $\mathrm{SAH}$ in coma recover without any marked neurological deficits and cognitive functions disorders. Van Heuven et al. ${ }^{23}$, on the other hand, indicated that patients who are admitted to hospital and give no verbal or

Subarachnoid Hemorrhage. In the opinion of the authors, patients after SAH tend to experience memory deficit, as well as a decline in executive and language functions. Cognitive disorders affect everyday functioning, employability and the quality of life. motor response have a $5 \%$ chance to recover and function independently.

Our study showed statistically significant correlations between the applied functional scales, which is confirmed in the research conducted by other authors who

Table 5. Results of Spearman's rank correlation analysis

\begin{tabular}{|l|c|c|c|}
\multicolumn{1}{c|}{ Scale } & FCS & BI & mRS \\
\hline FCS & - & $r_{S}=-0.78, p=0.0003^{*}$ & $r_{S}=0.68, p=0.0001^{*}$ \\
\hline BI & $r_{S}=-0.78, p=0.0003^{*}$ & - & $r_{S}=-0.83, p=0.0001^{*}$ \\
\hline mRS & $r_{S}=0.68, p=0.0001^{*}$ & $r_{S}=-0.83, p=0.0001^{*}$ & $r_{S}=0.83, p=0.0001^{*}$ \\
\hline GOS & $r_{S}=-0.69, p=0.0001^{*}$ & $r_{S}=0.83, p=0.0001^{*}$ & $r_{S}=-0.88, p=0.0004^{*}$ \\
\hline
\end{tabular}

$r_{\text {s }}$ - correlation coefficient; ${ }^{*}$ - statistically significant. 
use various measuring instruments in clinical (Hunt and Hess Scale, World Federation of Neurological Surgeons Scale, Glasgow Coma Scale, Fisher Scale) $7,24,25$ and functional assessment (Barthel Index, Rankin Scale, Glasgow Outcome Scale, SF-36) ${ }^{26,27}$ carried out both in the early and late period after the treatment of intracranial aneurysm.

\section{Conclusions}

The study shows that the FCS correlates with other scales used in the assessment of the condition of patients with intracranial aneurysm, which means that the proposed tool can be used in practice.

The clinical condition and consciousness level of a patient before the procedure constitutes a factor that differentiates his or her functional condition after the procedure.

The FCS should be further subjected to multicentre randomized research in order to provide more detailed conclusions.

\section{References}

1. Rinkel GJ, Algra A. Long-term outcomes of patients with aneurysmal subarachnoid haemorrhage. Lancet Neurol. 2011;10:349-356.

2. Lanzino G, Crobeddu E. Can we predict rebleeding after aneurysmal subarachnoid hemorrhage (SAH)? World Neurosurg. 2011;76:253-254.

3. Bor AS, Rinkel GJ, van Norden J, Wermer MJH. Long-term, serial screening for intracranial aneurysms in individuals with a family history of aneurysmal subarachnoid haemorrhage: A cohort study. Lancet Neurol. 2014;13:385-392.

4. Pyysalo LM, Niskakangas TT, Keski-Nisula LH, Kähärä VJ, Öhman JE. Long-term outcome after subarachnoid haemorrhage of unknown etiology. J Neurol Neurosurg Psychiatry. 2011;82:1264-1266.

5. Wermer MJH, Greebe P, Algra A, Rinke GJE. Long-term mortality and vascular event risk after aneurysmal subarachnoid haemorrhage. J Neurol Neurosurg Psychiatry. 2009;80:1399-1401.

6. Molyneux AJ, Kerr R, Stratton I, et al. International Subarachnoid Aneurysm Trial (ISAT) Collaborative Group. International Subarachnoid Aneurysm Trial (ISAT) of neurosurgical clipping versus endovascular coiling in 2143 patients with ruptured intracranial aneurysms: A randomised trial. Lancet. 2002;360:1267-1274.

7. Molyneux AJ, Kerr R, Yu LM, et al. International Subarachnoid Aneurysm Trial (ISAT) Collaborative Group. International subarachnoid aneurysm trial (ISAT) of neurosurgical clipping versus endovascular coiling in 2143 patients with ruptured intracranial aneurysms: A randomised comparison of effects on survival, dependency, seizures, rebleeding, subgroups, and aneurysm occlusion. Lancet. 2005;366:809-817.

8. Molyneux AJ, Kerr RS, Birks J, et al. ISAT Collaborators. Risk of recurrent subarachnoid haemorrhage, death, or dependence and standardised mortality ratios after clipping or coiling of an intracranial aneurysm in the International Subarachnoid Aneurysm Trial (ISAT): Long-term follow-up. Lancet Neurol. 2009;8:427-433.

9. McDougall CG, Spetzler RF, Zabramski JM, et al. Albuquerque FC. The Barrow Ruptured Aneurysm Trial. J Neurosurg. 2012;116:135144.

10. Teasdale G, Jennett B. Assessment of coma and impaired consciousness: A practical scale. Lancet. 1974;2:81-83.

11. Hunt WE, Hess RM. Surgical risk as related to time of intervention in the repair of intracranial aneurysms. J Neurosurg. 1968;28:14-20.

12. Report of World Federation of Neurological Surgeons Committee on a Universal Subarachnoid Hemorrhage Grading Scale. J Neurosurg. 1988;68:985-986.

13. Mahoney FI, Barthel DW. Functional evaluation: The Barthel Index. Md State Med J. 1965;14:56-61.

14. van Swieten JC, Koudstaal PJ, Visser MC, Schouten HJ, van Gijn J. Interobserver agreement for the assessment of handicap in stroke patients. Stroke. 1988;19:604-607.

15. Jennett $B$, Bond M. Assessment of outcome after severe brain damage: A practical scale. Lancet. 1975;1:480-484.

16. Ślusarz R, Biercewicz M, Rybicka R, Beuth W, Śniegocki M. Functional capacity of patients in the early period after the embolization of cerebrovascular malformations: Preliminary findings. J Neurosci Nurs. 2012;44:253-259.

17. Ślusarz R, Biercewicz M, Rybicka R. Functional capacity scale in assessment of patients with intracranial aneurysms: Reliability and validity. J Neurosci Nurs. 2014;46:46-54.

18. Al-Khindi T, Macdonald RL, Schweizer TA. Cognitive and functional outcome after aneurysmal subarachnoid hemorrhage. Stroke. 2010;41:e519-536.

19. Shirao $\mathrm{S}$, Yoneda $\mathrm{H}$, Kunitsugu I, et al. Preoperative prediction of outcome in 283 poor-grade patients with subarachnoid hemorrhage: A project of the Chugoku-Shikoku Division of the Japan Neurosurgical Society. Cerebrovasc Dis. 2010;30:105-113.

20. Salary M, Quigley MR, Wilberger JE Jr. Relation among aneurysm size, amount of subarachnoid blood, and clinical outcome. J Neurosurg. 2007;107:13-17.

21. Taki W, Sakai N, Suzuki H. Determinants of poor outcome after aneurysmal subarachnoid hemorrhage when both clipping and coiling are available: Prospective Registry of Subarachnoid Aneurysms Treatment (PRESAT) in Japan. World Neurosurg. 2011;76:437445.

22. Haug T, Sorteberg A, Finset A, Lindegaard KF, Lundar T, Sorteberg W. Cognitive functioning and health-related quality of life 1 year after aneurysmal subarachnoid hemorrhage in preoperative comatose patients (Hunt and Hess grade V patients). Neurosurgery. 2010;66:475-484.

23. van Heuven AW, Dorhout Mees SM, Algra A, Rinkel GJ. Validation of a prognostic subarachnoid hemorrhage grading scale derived directly from the Glasgow Coma Scale. Stroke. 2008;39:1347-1348.

24. Degen LA, Dorhout Mees SM, Algra A, Rinkel GJ. Interobserver variability of grading scales for aneurysmal subarachnoid hemorrhage. Stroke. 2011;42:1546-1549.

25. Koivisto T, Vanninen R, Hurskainen H, Saari T, Hernesniemi J, Vapalahti M. Outcomes of early endovascular versus surgical treatment of ruptured cerebral aneurysms: A prospective randomized study. Stroke. 2000;10:2369-2377.

26. Kim DH, Haney CL, Van Ginhoven G. Utility of outcome measures after treatment for intracranial aneurysms: A prospective trial involving 520 patients. Stroke. 2005;36:792-796.

27. Kirkness CJ, Thompson JM, Ricker BA, et al. The impact of aneurysmal subarachnoid hemorrhage on functional outcome. J Neurosci Nurs. 2002;34:134-141. 